\title{
A pre- post-evaluation of implementing an inpatient warfarin monitoring and education program
}

\author{
Edward P. ARMSTRONG, Lucy CHEMODUROW, Shanna CHRISTENSEN, E. Suzanne JOHNSON.
} Received (first version): 2-Nov-2010 Accepted: 29-May-2011

\begin{abstract}
${ }^{*}$
Objective: The purpose of this study was to evaluate whether a new anticoagulation management program resulted in better monitoring of warfarin, increased warfarin patient education prior to discharge, and fewer bleeding complications associated with warfarin.
\end{abstract}

Methods: A retrospective chart review was conducted of patients who were inpatients and received warfarin from April 1, 2008 to July 31, 2008 (control group) and from April 1, 2009 to July 31, 2009 (after implementation of the new anticoagulation program). The frequency of warfarin-related laboratory orders that included international normalized ratios (INRs), complete blood counts (CBCs), and documented patient education by pharmacy, nursing, and dietary services were determined before and after program implementation. Also, data was collected to determine frequencies of bleeding complications associated with warfarin.

Results: There were 112 patients in the pre- and 115 patients in the post-program group. After implementation of the inpatient warfarin management program, obtaining baseline INRs increased from $74 \%$ to $90 \%(p=0.001)$. Orders for baseline CBCs increased from $85 \%$ to $94 \%$ $(p=0.026)$. Obtaining CBCs every 3 days increased from $54 \%$ to $74 \%,(p<0.001)$. However, there was no significant change in orders for daily INRs $(p=0.055)$. Education by nursing increased from $54 \%$ to $80 \%,(p<0.001)$, by pharmacy increased from $8 \%$ to $76 \%,(p<0.001)$, and by dietary increased from $11 \%$ to $79 \%,(p<0.001)$.

Documentation by all three disciplines in each patient increased from $3.6 \%$ to $59 \%,(p<0.001)$. Significantly fewer patients received vitamin $\mathrm{K}$ and/ or fresh frozen plasma for supratherapeutic INRs with bleeding complications after the program was initiated compared to baseline $(p=0.009)$.

Conclusion: The implementation of an inpatient warfarin management program led to better monitoring of patients receiving warfarin, and increased patient education. However, a larger and longer assessment is necessary to determine if

\footnotetext{
Edward P. ARMSTRONG, Pharm.D. College of Pharmacy, University of Arizona. Tucson, Arizona (United States).

Lucy CHEMODUROW, Pharm.D. College of Pharmacy, University of Arizona. Tucson, Arizona (United States). Shanna CHRISTENSEN, Pharm.D. College of Pharmacy, University of Arizona. Tucson, Arizona (United States). E. Suzanne JOHNSON, Pharm.D., BCPS. Pharmacy Department, Carondelet St. Joseph's Hospital. Tucson, Arizona (United States).
}

these changes are maintained and how these changes affect long-term clinical outcomes.

Keywords: Warfarin. Inpatients. Pharmacy Service, Hospital. United States.

\section{EVALUACIÓN PRE- POST- DE LA IMPLANTACIÓN DE UN PROGRAMA EDUCATIVO Y DE MONITORIZACIÓN DE WARFARINA}

\section{RESUMEN}

Objetivo: El propósito de este estudio fue evaluar si un nuevo programa de manejo de la anticoagulación produjo mejor monitorización de la warfarina, aumentó la educación del paciente sobre warfarina antes del alta, y redujo las complicaciones hemorrágicas asociadas a la warfarina.

Métodos: Se realizó una revisión retrospectiva de los historiales de todos los pacientes hospitalizados que recibieron warfarina entre el 1-abril y 31-julio de 2008 (grupo control) y del 1-abril y 31-julio de 2009 (después de la implantación del nuevo programa de anticoagulación). Antes y después del programa se determinó la frecuencia de peticiones de laboratorio relacionadas con la warfarina que incluían ratios internacionales normalizados (INR), recuentos completos de células (RCC) y se documentó la educación al paciente por la farmacia, enfermería y servicios dietéticos. También se recogieron datos para determinar frecuencias de complicaciones hemorrágicas asociadas con la warfarina.

Resultados: Hubo 112 pacientes en el grupo pre- y 115 en el grupo post-programa. Después de la implantación del programa de manejo de warfarina en pacientes hospitalizados, la solicitud de INR aumentó de $74 \%$ a $90 \%$ ( $\mathrm{p}=0,001)$. Las solicitudes de RCC al inicio aumentaron de $85 \%$ a $94 \%$ ( $\mathrm{p}=0,026)$. La obtención de RCC cada 3 días aumentó de $54 \%$ a $74 \%,(p<0,001)$. Sin embargo, no hubo cambios significativos en las solicitudes de INR diario $(p=0,055)$. La educación por enfermeras aumentó de $54 \%$ a $80 \%$, ( $<<0,001)$, por farmacia aumentó de $8 \%$ a $76 \%,(\mathrm{p}<0,001)$, y por dietistas aumentó de $11 \%$ a $79 \%,(\mathrm{p}<0,001)$. La educación por las tres disciplinas a cada paciente aumentó de $3,6 \%$ a $59 \%$, (p<0,001).En comparación con el inicio, después de iniciarse el programa hubo menos pacientes que recibieron vitamina $\mathrm{K}$ y/o plasma fresco congelado para INR excesivos con complicaciones hemorrágicas $(\mathrm{p}=0,009)$. 
Conclusión: La implantación de un programa de manejo de warfarina en hospitalizados llevó a una mejor monitorización de pacientes que reciben warfarina, y a una mayor educación a pacientes. Sin embargo, se necesita una evaluación mayor y más prolongada para determinar si estos cambios se mantienen y como afectan a los resultados clínicos a largo plazo.

Palabras clave: Warfarina. Hospitalizados. Servicio de Farmacia, Hospital. Estados Unidos.

\section{INTRODUCTION}

Warfarin is an effective anticoagulant used to prevent and treat blood clots in numerous disease states. It is the most commonly used oral anticoagulant in the United States. ${ }^{1}$ However its use also poses serious risks to patients. Warfarin therapy requires individualized dosing and intensive laboratory monitoring to achieve optimal patient outcomes and minimize the risk of serious adverse events, such as bleeding complications or thromboembolic events. The intense monitoring of patients on warfarin includes following their international normalized ratio (INR), monitoring complete blood count values, and monitoring patient compliance and adherence to therapy. The INR is a standardized test used by clinicians to measure and monitor the degree of anticoagulation. ${ }^{2}$

Due to the inherent risk associated with the use of anticoagulation products, many patient safety groups and national hospital accreditation organizations are encouraging healthcare institutions to develop and implement strategies to improve the safe use of anticoagulation products. ${ }^{3-5}$ For example, to maximize the benefits of anticoagulation therapy while minimizing the adverse effects of warfarin, The Joint Commission is asking organizations to reduce the likelihood of patient harm associated with the use of anticoagulation therapy in their National Patient Safety Goal $03.05 .01 .^{5}$ A number of studies have found that coordinating care and providing a systematic approach to anticoagulation therapy has resulted in patients achieving optimal therapy and at the same time decreasing the number of adverse effects associated with its use. ${ }^{6-13}$

To improve patient safety and to assess and improve anticoagulation therapy in their facility, a community hospital developed and implemented an anticoagulation management program. Inpatients have numerous issues that can affect warfarin responsiveness (e.g., diet, concurrent disease, medications) and are inherently medically unstable. Therefore, the community hospital approved a policy which required a baseline and daily INR and a baseline and every three day complete blood count (CBC) to be monitored. ${ }^{14}$ The purpose of this study was to examine the impact of this program related to the management of inpatient warfarin therapy. Attention was focused on process measures of laboratory monitoring, provision of education by three professionals, and whether bleeding complications occurred.

\section{METHODS}

This study was a pre- post- chart review study at an inpatient hospital that had implemented a new anticoagulation management program beginning January 1, 2009. The historical control group, before implementation of the new anticoagulation program, was inpatients receiving warfarin during the time period of April 1, 2008 to July 31, 2008. Information about the new anticoagulation management program was provided to all employees of the hospital beginning in October 2008. Education about the new program was provided to nursing and dietary staff via Internet based training. Pharmacy employees completed an educational competency on the program. Fliers were sent to all employees regarding the new policies and procedures. Also, information regarding the new anticoagulation program was provided in the hospital's circulating pharmacy newsletter.

The post-program data collection occurred for inpatients receiving warfarin during the time period of April 1, 2009 to July 31, 2009. Inclusion criteria for the study were inpatients receiving warfarin during the aforementioned pre- and post-time periods. Exclusion criteria were patients with a length of stay of less than 5 days and duration of warfarin therapy less than 5 days. Patients were identified by searching pharmacy records to find discharged patients that received warfarin. This study was approved by both the University of Arizona Human Subjects Protection Program as well as the Human Subjects Committee of the community hospital before beginning data collection.

The independent variable in this study was the implementation of a new anticoagulation management program. The dependent variables were as follows: 1) appropriateness of warfarin monitoring (was there a baseline INR, daily INR, baseline CBC, and CBC obtained every 3 days); 2) patient education about warfarin therapy provided by hospital professional staff (documented by nursing, pharmacy, dietary services, and by all disciplines for each patient); 3) clinically significant (i.e., major bleeding) bleeding complication (defined as evidence of bleeding (e.g., epistaxis), vitamin $\mathrm{K}$ administration, and/ or- use of blood products/transfusions). Data collected included patient gender, age, weight, height, and race/ethnicity, disease characteristics, indication for anticoagulation therapy, and whether patients were admitted on warfarin therapy or were started on warfarin therapy in the hospital.

Statistical analysis was performed with SPSS version 18. The a priori alpha level for statistical significance was less than 0.05 . Descriptive statistics (means, SD, frequency counts) were conducted to describe the demographic variables of the enrolled population and the indication for treatment. Independent t-test was used to compare means between pre- and post-time periods. To compare appropriateness of laboratory monitoring, 


\begin{tabular}{|l|c|c|c|}
\hline Table 1. Patient Demographic Characteristics & \multicolumn{2}{c|}{} \\
\hline Characteristic & $\begin{array}{c}\text { Pre-group } \\
\mathrm{n}=112\end{array}$ & $\begin{array}{c}\text { Post-group } \\
\mathrm{n}=115\end{array}$ & P Value \\
\hline Age, mean (SD), years & $73(13.76)$ & $72(14.44)$ & 0.65 \\
\hline Weight, mean, (SD), kg & $77.90(24.18)$ & $79.37(23.08)$ & 0.638 \\
\hline Height, mean (SD), cm & $166.73(9.40)$ & $166.92(11.52)$ & 0.892 \\
\hline Gender, \% & $46 \%$ & $45 \%$ & 0.96 \\
Male & $54 \%$ & $55 \%$ & 0.534 \\
Female & & & \\
\hline Race/ ethnicity, \% & $87 \%$ & $86 \%$ & \\
White & $8.9 \%$ & $7.8 \%$ & \\
Hispanic & $4.5 \%$ & $3.5 \%$ & \\
Black & 0 & $0.86 \%$ & \\
Asian & 0 & $7.7 \%$ & \\
Other & & & \\
\hline
\end{tabular}

the frequencies of warfarin-related laboratory orders (that include a baseline INR, daily INR, baseline CBC, CBC every 3 days) the documentation of patient education provided by pharmacy, nursing, and dietary services were compared using a chisquared test. Bleeding complications between the pre-and post- groups were compared using a Fisher's exact test. Before beginning data collection, the required sample size was estimated. Assuming a baseline success rate of $50 \%$ of patients having all baseline laboratory tests obtained, an alpha level of 0.05 and a beta level of 0.2 (80\% power), 103 patients per group would be needed to detect a $20 \%$ improvement (i.e., reaching $70 \%$ compliance) in obtaining all baseline laboratory data.

\section{RESULTS}

There were 112 patients who received warfarin as an inpatient in the timeframe of April 2008-July 2008 and these patients were compared with 115 patients who received warfarin as an inpatient in the timeframe of April 2009-July 2009. The demographic characteristics of pre- and postgroups are shown in Table 1. All baseline characteristics were similar between the two cohorts. Indications for warfarin therapy were also similar between the groups, summarized in Table 2 . The target INR range for the majority of patients was 2.0-3.0 (Table 2). Patients who were being treated after receiving a coronary artery stent or a prosthetic heart valve had a desired INR range of 2.5-3.5.

The ordering frequency of all laboratory tests increased after implementation of the inpatient warfarin program (Figure 1). Obtaining INRs at baseline increased from $74 \%$ before the program was started to $90 \%$ after implementation $(p=0.001)$. Orders for baseline CBCs increased from $85 \%$ in baseline to $94 \%$ after the program was started $(p=0.026)$. In addition, obtaining CBCs every 3 days increased from $54 \%$ before to $77 \%$ after the program $(p<0.001)$. However, although orders for daily INRs increased from $52 \%$ before to $64 \%$ after implementing the program, this difference was not statistically significant $(p=0.055)$.

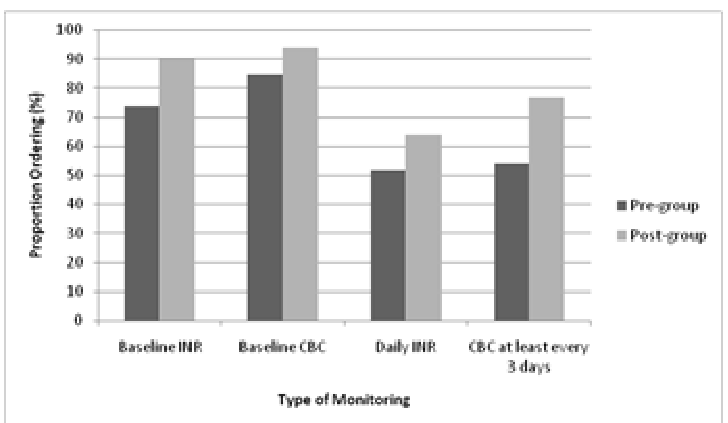

Figure 1. Frequency of appropriate warfarin laboratory monitoring.

Warfarin education provided prior to discharge significantly increased for nursing, pharmacy, and dietary services (Figure 2). Specifically, education provided by nursing staff increased from $54 \%$ at baseline to $80 \%$ after the program was started $(p<0.001)$. Education by pharmacy staff increased from $8 \%$ at baseline to $76 \%$ following the new program $(p<0.001)$. Education by dietary services increased from $11 \%$ at baseline to $79 \%$ after the new program $(p<0.001)$. Moreover, documentation by all three disciplines in each patient record increased significantly from $3.6 \%$ at baseline to $59 \%$ after the program was started $(p<0.001)$.

\begin{tabular}{|l|c|c|c|}
\hline Table 2. Indications for warfarin therapy & $\begin{array}{c}\text { Pre-group } \\
\mathrm{n}=112\end{array}$ & $\begin{array}{c}\text { Post-group } \\
\mathrm{n}=115\end{array}$ & P Value \\
\hline Characteristics & $55(49 \%)$ & $52(45 \%)$ & 0.522 \\
\hline Patients admitted on warfarin, No., (\%) & $13(11 \%)$ & $21(18 \%)$ & 0.519 \\
\hline Indication for warfarin therapy, No., (\%) & $16(14 \%)$ & $12(10 \%)$ & \\
DVT & $32(29 \%)$ & $26(23 \%)$ \\
PE & $38(34 \%)$ & $37(32 \%)$ & \\
Orthopedic surgery & $4(3.6 \%)$ & $3(2.6 \%)$ & \\
Atrial fibrillation & $2(1.7 \%)$ & $3(2.6 \%)$ & \\
Prosthetic heart valve & $7(6.3 \%)$ & $13(11 \%)$ & 0.675 \\
Unknown/ undocumented & $108(96 \%)$ & $112(97 \%)$ & \\
Other & $4(3.6 \%)$ & $3(2.6 \%)$ & 0.085 \\
\hline Therapeutic INR range, No. (\%) & $112(100 \%)$ & $112(97 \%)$ & \\
2-3 & 0 & 3 & \\
$2.5-3.5$ & & & \\
\hline Provider managing warfarin therapy, No., (\%) & & & \\
Physician & & & \\
Pharmacist &
\end{tabular}




\begin{tabular}{|l|c|c|c|}
\hline Table 3. Bleeding complications & $\begin{array}{c}\text { Pre-group } \\
n=112\end{array}$ & $\begin{array}{c}\text { Post-group } \\
n=115\end{array}$ & $P$ Value \\
\hline Major bleeding documented, No. & 3 & 0 & 0.118 \\
Minor bleeding documented, No. & 8 & 3 & 0.132 \\
\hline
\end{tabular}

\begin{tabular}{|l|c|c|c|}
\hline Table 4. Administration of Vitamin K and/ or Fresh Frozen Plasma (FFP) \\
\hline Type of product used & $\begin{array}{c}\text { Pre-group } \\
\mathrm{n}=112\end{array}$ & $\begin{array}{c}\text { Post-group } \\
\mathrm{n}=115\end{array}$ & P Value \\
\hline Vitamin K given, No., (\%) & $17(15 \%)$ & $19(16 \%)$ & 0.782 \\
\hline FFP given, No., (\%) & $12(11 \%)$ & $7(6 \%)$ & 0.208 \\
\hline Indication for Vit K and/ or FFP to be given, No. (\%) & $\mathrm{n}=22$ & $\mathrm{n}=21$ & 0.012 \\
Before surgery/procedure & $3(14 \%)$ & $8(38 \%)$ & 0.215 \\
Supratherapeutic INR w/o bleeding & $10(45 \%)$ & $12(57 \%)$ & 0.701 \\
Supratherapeutic w/ bleeding & $9(41 \%)$ & $1(4.8 \%)$ & $0.009^{*}$ \\
\hline \multicolumn{4}{|l|}{ denotes statistical significance }
\end{tabular}

There were significantly fewer patients receiving vitamin $\mathrm{K}$ and/ or fresh frozen plasma for supratherapeutic INRs with bleeding complications after the program was initiated compared to baseline $(p=0.009)$. The pre-group had 9 patients versus 1 patient in the post-group that received vitamin $\mathrm{K}$ and/or fresh frozen plasma for an elevated INR level combined with a bleeding complication.

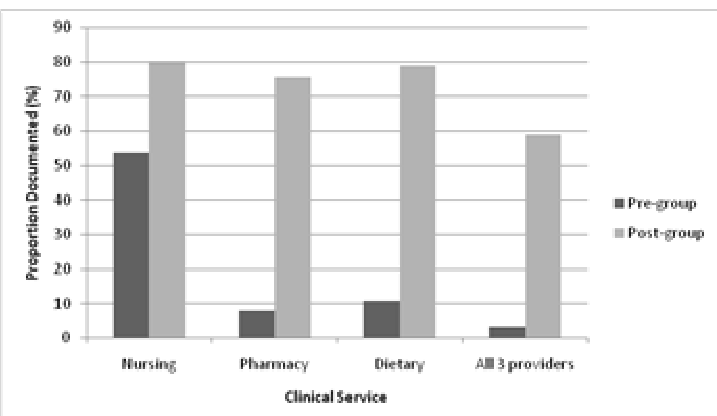

Figure 2. Frequency of warfarin education provided to patients upon discharge.

Major bleeding complications occurred in 3 patients in the pre-group and 0 patients in the post-group; however, this difference was not statistically significant $(p=0.118)$, see Table 3 . Of the 3 patients found to have major bleeding complications 2 patients were admitted through the Emergency Department with supratherapeutic INRs in conjunction with bleeding complications. The first patient was found to have epistaxis lasting greater than 3 days and the second patient presented with a large bleeding hematoma on his leg. The third patient had a supratherapeutic INR during their hospital stay with an undocumented bleeding complication that required vitamin $\mathrm{K}$, fresh frozen plasma, and packed red blood cells. There were 8 patients in the pre-group that developed minor bleeding complications versus 3 in the post-group; this difference was not statistically significant $(p=0.132)$. Of the 8 minor bleeding complications in the pre-group, all had supratherapeutic INRs, 4 experienced hematuria, and the other 4 experienced epistaxis. The 4 minor bleeding complications experienced in the post-group were all documented as hematuria. There were 17 patients in the pre-group versus 19 patients in the post-group who received vitamin $K(p=0.782)$, see Table 4. Fresh frozen plasma administration did not differ significantly between the groups. In addition, there was no difference between patients receiving vitamin $\mathrm{K}$ and/ or fresh frozen plasma for supratherapeutic INRs without bleeding complications.

\section{DISCUSSION}

The results of this study indicate that the implementation of the an inpatient warfarin management program significantly improved laboratory monitoring, interdisciplinary teaching, and was associated with fewer patients receiving vitamin $\mathrm{K}$ and/ or fresh frozen plasma for supratherapeutic INRs with bleeding complications. These results emphasize the importance of warfarin therapy, the role of multiple professionals in monitoring and educating patients, and the risk of this treatment.

The improved results following implementation of the warfarin management program is similar to a number of earlier studies that found coordinating care and providing a systematic approach to anticoagulation therapy resulted in patients achieving optimal therapy and at the same time decreasing the number of adverse effects associated with anticoagulation therapy. ${ }^{6-16}$

For example, Lanefeld et al. performed a randomized controlled trial and found that an inpatient anticoagulation guideline-based consultation service was associated with reduction in the frequency of anticoagulant-related bleeding in patients at increased risk for major in-hospital bleeding. ${ }^{15}$ Their guideline-based consultation included individualized review of the risks and benefits of anticoagulant therapy and on the basis of current practice guidelines, recommendations for daily management. They reasoned that consultation using current practice guidelines could improve physician use of anticoagulant therapy. Similarly, Touchette et al. demonstrated that a pharmacistinitiated intervention improved outpatient warfarin use for hospitalized patients with atrial fibrillation. ${ }^{16}$

There are several limitations with the current study. In order to possibly see a difference in clinically significant bleeding complications with the warfarin program, a study using a larger sample size, and longer time periods should be performed. Also, the post-implementation time period was 4 months after the initiation of the program. A later time period 
might have seen an even greater increase in frequency of laboratory monitoring, patient education, and a possible difference in bleeding complications.

In addition, this study was designed to also determine the time in the therapeutic range of INR values. However, due to the length of time required to measure the full warfarin effect combined with the short length of hospital stay for many patients, there were only a limited number of data points available to calculate time in the therapeutic range.

Another inherent limitation of this study is the singlelocation. In addition, data collection was limited to the variables identified in the medical records. For example, education may have been provided by a clinician, but was not documented in the medical record. In some circumstances, patients discharged to hospice, rehabilitation centers, or long-term care facilities may have had education withheld. Also, documentation within the chart was relied upon to identify bleeding complications.

\section{CONCLUSIONS}

The implementation of this program focused on the use of a standardized process in an effort to establish a structured approach to managing warfarin therapy in an inpatient setting. The adoption of this intervention resulted in a significant improvement in anticoagulation management, particularly with increased laboratory monitoring and interdisciplinary education by nursing, pharmacy, and dietary services. Overall, this model represents an intervention in anticoagulation management that could be readily implemented and duplicated at most any facility providing inpatient warfarin therapy.

\section{CONFLICT OF INTEREST}

No authors have any type of conflict of interest to declare for this study.

\section{References}

1. Pengo V, Pegoraro C, Cucchini U, lliceto S. Worldwide management of oral anticoagulant therapy: the ISAM study. J Thromb Thrombolysis. 2006;21:73-77.

2. Dolan G, Smith LA, Collins S, Plumb JM. Effect of setting, monitoring, intensity and patient experience on anticoagulation control: a systematic review and meta-analysis of the literature. Curr Med Res Opin. 2008;24:14591472.

3. Anonymous. NPSGs target anticoagulation therapy, patient deterioration. Healthcare Benchmarks Qual Improv. 2007; $14: 97-101$

4. Quinsey CA. The National Quality Forum: in search of patient safety. J Am Assoc Med Transcript. 2004;23:86-88.

5. The Joint Commission. National patient safety goals. 2010 national patient safety goals (NPSGs). Available at: www.jointcommission.org/PatientSafety/NationalPatientSafetyGoals/ (Accessed 2010 Oct 20).

6. Matchar DB. Do anticoagulation management services improve care? Implications of managing anticoagulation services trial. Cardiac Electrophysiol Rev. 2003;7:379-381.

7. Witt DM, Sadler MA, Shanahan RL, Mazzoli G, Tillman DJ. Effect of a centralized clinical pharmacy anticoagulation service on the outcomes of anticoagulation therapy. Chest. 2005;127:1515-1522.

8. Wilson SJ, Wells PS, Kovacs MJ, Lewis GM, Martin J, Burton E, Anderson DR. Comparing the quality of oral anticoagulation management by anticoagulation clinics and by family physicians: a randomized controlled trial. CMAJ. 2003;169:293-298.

9. Biscup-Horn PJ, Streiff MB, Ulbrich TR, Nesbit TW, Shermock KM. Impact of an inpatient anticoagulation management service on clinical outcomes. Ann Pharmacother. 2008;42:777-782.

10. Errichetti AM, Holden A, Ansell J. Management of oral anticoagulation therapy. Experience with an anticoagulation clinic. Arch Intern Med. 1984;144:1966-1968.

11. Cohen IA, Hutchison TA, Kirking DM, Shue ME. Evaluation of a pharmacist-managed anticoagulation clinic. J Clin Hosp Pharm. 1985;10:167-175.

12. Ford ND, Hale LS. Measuring the effectiveness of an in-patient, pharmacist-managed anticoagulation service. Available at: http://hdl.handle.net/10057/593 (accessed 2011 April 14).

13. Dager WE, Branch JM, King JH, White RH, Quan RS, Musallam NA, Albertson TE. Optimization of inpatient warfarin therapy: impact of daily consultation by a pharmacist-managed anticoagulation service. Ann Pharmacother. 2000;34:567-572.

14. Gulseth M. Daily INR Policy, St. Mary's Medical Center, Duluth, MN, Pharmacy Policy and Procedure Manual. In: Gulseth M, ed. Managing Anticoagulation Patients in the Hospital: The Inpatient Anticoagulation Service. Bethesda, MD: American Society of Health-System Pharmacists; 2007:57.

15. Landefeld CS, Anderson PA. Guideline-based consultation to prevent anticoagulation-related bleeding. A randomized, controlled trial in a teaching hospital. Ann Intern Med. 1992;116:829-837.

16. Touchette DR, McGuinness ME, Stoner S, Shute D, Edwards JM, Ketchum K. Improving outpatient warfarin use for hospitalized patients with atrial fibrillation. Pharmacy Practice (Internet).2008;6(1):43-50. 